\title{
SCIENTIFIC LIFE
}

\section{Inexpensive research in the golden open access era}

\author{
Samuel Alizon
}

\begin{abstract}
The financial pressure that publishers impose on libraries is a worldwide concern. Gold open access publishing with an expensive article processing charge paid by the authors is often presented as an ideal solution to this problem. However, such a system threatens less funded departments and even article quality.
\end{abstract}

Keywords: open access; peer review; funding; publishing; journals; megajournals

\section{No money, no submission}

The financial pressure that publishers impose on institutional libraries is a worldwide concern, which has led to increasing support for open access publishing [1]. Gold open access (terms in bold are in the Glossary) with an article processing charge (APC) paid by the authors is often presented as an ideal compromise: publishers can still charge high publication fees, while everyone can access the literature for free without delay. As recent history illustrates, this system is dangerous for theoretical evolutionary ecologists, and, more generally, for researchers working in fields with low funding.

In May 2017, three students and I submitted a manuscript on modelling ebola virulence evolution to a new society journal run by a well-established publisher. This research project had been conducted independently of any specific grant. The journal being open-access-only, we were asked to confirm that we would pay more than $2,000 €$ upon acceptance. This will appear as a negligible fee to some but by French standards at least it is not (besides grant money flagged for specific projects, my colleagues and I's research allowance is $4,000 €$, and this is more than in most French ecology \& evolution departments). We therefore declined the offer and received an automatic email informing us that the publisher had asked the editorial office to withdraw our manuscript. In the end, I contacted the chief editor who informed me he never got to see the submission and we submitted the article elsewhere [2]. Ironically, I had already reviewed 3 manuscripts for this new journal.

Correspondence: samuel.alizon@cnrs.fr

Laboratoire MIVEGEC (UMR 5290 CNRS, IRD, UM), 911, avenue Agropolis, BP 64501, 34394 Montpellier, France

Full list of author information is available at the end of the article

\section{Publishing costs are dropping}

With the advent of online publishing, costs have dropped considerably, as supported by some indicators. At one extreme, the bioRxiv repository costs less then $10 \$$ per preprint [3]. It does not include any typesetting or reviewing, but it does check for plagiarism and offers a Digital Object Identifier (DOI), a built-in search engine and links to social media. This explains why some open access journals can run without APCs and why predatory journals proliferate. The transparency of the non-profit publisher Public Library of Science (PLoS) can also be used to estimate publication costs. In 2016, PLoS declared 43 million USD in expenses and published more than 27,000 open access articles [4]. However, the resulting $1500 \$$ per article most likely overestimates the true publishing cost since PLoS' budget includes questionable expenses such as 'lobbying' or shocking salaries $(830,216 \$$ for their two CEOs in 2013) [5]. The numbers in Table 1, which mostly originate from a 2009 report [6], suggest that the cost per paper is likely to be lower than $900 \$$ per article. Importantly, two thirds of this cost correspond to editing and proofreading; two steps that are increasingly neglected in many journals and becoming less time-consuming with new softwares.

Even with our most conservative estimates, publishing costs should have dropped significantly over the last two decades. Instead, we are witnessing the opposite, and open access plays a pivotal role in this illogical trend.

\section{The open access excuse}

That anyone can access top level scientific publications is commendable. However, this is currently being used as an excuse to maintain, if not increase, profits 
from publishing. If the goal is to disseminate research, green open access is almost equally efficient. One of the sole limitations is that journals typically impose a 6 to 12 months embargo [1]. Regardless, nowadays it only takes an email to an author to (legally) obtain a copy of an article. Cynically speaking, the reason why many new journals are open-access-only is probably that publishers have realised they will soon be unable to sell their journals and therefore wish to see the money up front.

At first glance, this issue can appear as a mere budget problem: institutions should shift some funding from libraries to research grants. But the problem is more acute. Indeed, the generalisation of expensive APCs implies that research performed in the absence of grants cannot be published in relevant journals. According to the Directory of Open Access, most open access journals do not charge any APC at all, but unfortunately the articles they publish are marginal, at least in ecology and evolution. In fact, more 'influential' journals tend to have significantly higher APCs [7]. This is worrying because it supports the logic according to which an expensive article is a good one, when the APC is by no means an honest signal.

It is already problematic that for-profit corporations own so many prestigious journals. However, one of the hallmarks of serious journals has always been the symbolic wall separating the editorial board's decision from the publisher's interests. High APCs breach this wall by giving publishers the power to reject an article for financial reasons. Indirectly, they also give funding bodies the power to decide which research is legitimate.

\section{Quantity against quality}

In a broader context, the economic model where authors bear all the APC is ethically dangerous because it de facto creates an alignment of interests between a publishing company that wishes to maximise its profits and an author who wants a longer publication list. Far from being criticised, this model has prospered: since 2006 most publishers have followed PLoS ONE's example and launched their own megajournal. These have in common a light reviewing process to ensure that the research is sound and high acceptance rates (typically greater than $50 \%[8]$ ). The justification for this model is usually the hypothesis that post-publication reviewing will eventually sort out the important and relevant articles. More pragmatically, megajournals are extremely profitable to publishers and their articles are often put on the same standards as that of regular journals. Expensive open-access-publishing by society journals is therefore problematic because it further blurs the line between preprints and rigorously peerreviewed articles.
In 2010, molecular biologist Laurent Ségalat wrote on the analogy between the publication and the financial systems [9]. His worry was that the 'publication frenzy' and the global competition for very limited slots in high impact factor journal might lead to a disaster comparable to the 2008 financial crisis because in both cases short-term gains drive the whole system, a happy few become increasingly rich (or published) and there is little oversight. A few years later, the logic he was criticizing, that is publishing as goal in itself, is more prevalent than ever and high APCs are making things even worse by bringing large amounts of money into the interaction between researchers and publishers.

\section{Towards quality articles with low APC}

In their 2017 call for Open Science and Bibliodiversity, the stakeholders of Open Access scientific publishing insisted that costs should neither be paid by the readers nor by the authors and that "many fair funding models exist' such as institutional support or open archives [10]. Ensuring low APCs will not solve all problems, starting with how articles are selected. But it will at least avoid biasing publications in favour of wealthy fields or departments. It will also avoid having money becoming central in the interaction between authors and journals.

The remaining worry is the rigorous peer-review step. Without it, publications will be read based on authors' reputation or social media coverage. In passing, it is ironic that the key step to justify high APCs is the one that usually costs publishers nothing. Given the increase in the number of submitted manuscripts and the shortage of reviewers, we need to make good reviewing work more rewarding and useful. This is for instance the goal of 'Peer Community in' (PCI), a nonprofit initiative introduced by evolutionary biologists. Following a rigorous reviewing process, preprints recommended by PCI become valid references and can be considered of high value without the need for publication in classical journals (although the authors can still submit the preprint and the decision elsewhere). The whole process is free of charges and the website freely accessible [11].

Research institutions are also aware of the issue. In 2015 , it was estimated that all the subscriptions paid by libraries worldwide amounted to $5,000 €$ per article in the Web of Science [12]. This is probably what led the Howard Hughes Medical Institute, the Max Planck Society and the Wellcome Trust in 2012 to launch eLife, a high-level journal, independently of existing publishers. Unfortunately, in 2017 eLife switched to a system with an APC of $2500 \$$ [13], more than half of which supports marketing, editorials \& podcasts and 
even paying the editors and reviewers (33\% of eLife's 'publishing costs' in 2015). This is better than paying for PLoS' CEOs but it does feel strange to ask the authors of accepted articles to pay the editors and reviewers for their 'service'. Surely large public research institutions can come up with a fairer offer.

Help could also come from learned societies. A significant difficulty is that some earn a lot of money from journals edited by publishers. There is a debate to open but, isn't it more ethical to ask society members to pay for the society's activities (via conferences or membership fees)? Furthermore, since publishers are no philantropists, running their journals themselves might even be quite profitable to these societies. This option was not possible before, but with the decreasing costs of online only publishing it should be explored.

Initiatives such as bioRxiv and PCI demonstrate that technological advances from the last decades make it possible to make high-quality peer-reviewed publications from all researchers accessible to all with moderate, or even without, APC. Failure to do so will mean the victory of those for whom the processing charge of an article matters more than its contents.

\section{References}

1. Enserink, M. (2016) Dutch push for a quantum leap in open access, Science 352(6283), 279-279

2. Sofonea, M.T. et al. (2018) Can Ebola Virus evolve to be less virulent in humans?, J Evol Biol, in press, http://dx.doi.org/10.1111/jeb.13229

3. Van Noorden, R. (2013) Open access: The true cost of science publishing, Nature 495 (7442), 426

4. PLoS 2016 Annual Report (2016) Public Library of Science URL https :

//www.plos.org/files/PLOS-Annual-Update-2016-online.pdf, accessed on Feb 6, 2018.

5. Kern, A. (2016) Andrew Kern on PLoS (with tweets), Published online March 15, 2016. URL

https://storify.com/jtth/andrew-kern-on-plos, accessed on Feb 6, 2018.

6. Houghton, J. et al. (2009) Economic implications of alternative scholarly publishing models: Exploring the costs and benefits, Joint Information Systems Committee (JISC), URL http://www.jisc.ac.uk/media/documents/publications/ rpteconomicoapublishing.pdf, accessed on Feb 6, 2018.

7. West, J.D. et al. (2014) Cost effectiveness of open access publications, Econ Inq 52(4), 1315-1321.

8. Sugimoto, C.R. et al. (2013) Journal acceptance rates: A cross-disciplinary analysis of variability and relationships with journal measures, J Informetr 7(4), 897-906.

9. Ségalat, L. (2010) System crash: Science and finance: same symptoms, same dangers?, EMBO Reports 11(2), 86-89.

10. Jussieu Call for Open science and bibliodiversity, Published online Oct 10, 2017. URL http://jussieucall.org/, accessed on Feb 6, 2018.

11. Peer Community in ..., URL https://peercommunityin.org/, accessed on Feb 6, 2018.

12. Schimmer, R. (2015) Disrupting the subscription journals' business model for the necessary, http://dx.doi.org/10.17617/1.3

13. eLife (2016) Setting a fee for publication, Published online Sep 29, 2016, URL https://elifesciences.org/inside-elife/b6365b76/ setting-a-fee-for-publication

14. SHERPA RoMEO, Publisher copyright policies \& self-archiving, URL http://www.sherpa.ac.uk/romeo/, accessed on Feb 6, 2018.

\section{Funding}

SA acknowledges support from the Centre National de la Recherche Scientifique (CNRS) and the Institute de Recherche pour le Développement (IRD).

\section{Acknowledgements}

I thank the CNRS and the IRD for their support and Denis Bourguet, Nacho Bravo, Sébastien Lion, Carmen Lía Murall and Wolf Blanckenhorn for their suggestions.

\section{References}

1. M. Enserink, Dutch push for a quantum leap in open access, Science 352 (6283) (2016) 279-279.

2. M. T. Sofonea, L. Aldakak, L. F. Boullosa, S. Alizon, Can Ebola Virus evolve to be less virulent in humans?, J Evol Biol in press.

3. R. Van Noorden, Open access: The true cost of science publishing, Nature 495 (7442) (2013) 426.

4. PLoS 2016 Annual Report, Tech. rep., Public Library of Science (2016).

5. A. Kern, Andrew Kern on PLoS (with tweets), https://storify.com/jtth/andrew-kern-on-plos. URL https://storify.com/jtth/andrew-kern-on-plos

6. J. Houghton, B. Rasmussen, P. Sheehan, C. Oppenheim, A. Morris, C. Creaser, H. Greenwood, M. Summers, A. Gourlay, Economic implications of alternative scholarly publishing models: Exploring the costs and benefits, Tech. rep., Joint Information Systems Committee (JISC) (2009)

7. J. D. West, T. Bergstrom, C. T. Bergstrom, Cost effectiveness of open access publications, Econ Inq 52 (4) (2014) 1315-1321.

8. C. R. Sugimoto, V. Larivière, C. Ni, B. Cronin, Journal acceptance rates: A cross-disciplinary analysis of variability and relationships with journal measures, J Informetr 7 (4) (2013) 897-906.

9. L. Ségalat, System crash: Science and finance: same symptoms, same dangers?, EMBO Reports 11 (2) (2010) 86-89.

10. Jussieu Call for Open science and bibliodiversity. URL http://jussieucall.org/

11. Peer Community in ..., https://peercommunityin.org/. URL https://peercommunityin.org/

12. R. Schimmer, K. K. Geschuhn, A. Vogler, Disrupting the subscription journals' business model for the necessary.

13. Setting a fee for publication, eLife. URL https://elifesciences.org/inside-elife/b6365b76/ setting-a-fee-for-publication

14. SHERPA RoMEO, Publisher copyright policies \& self-archiving. URL http://www.sherpa.ac.uk/romeo/

\section{Glossary}

Acceptance rate Proportion of submitted articles that are accepted by a journal. It correlates with many features of the journal [8].

Article Processing Charge (APC) Publication fee charged to the author by the publisher. It is usually higher for open access articles because, in theory, the publisher should decrease subscription costs.

Digital Object Identifier (DOI) Unique and persistent identifier divided in two parts (the first part refers to the registrant, the second to the object). A consortium of publishers (CrossRef) centralises it for journals and books. Green Open Access Self-archiving from the author of the peer-reviewed (often non-typesetted) version of an article. Although not all journals allow for it [14], some countries permit it for most publications after a delay (e.g. 6 or 12 months in France).

Gold Open Access The final typesetted version of the article is made available free of charge to the reader and usually with a high APC to the author.

Megajournal open-access-only journal with a light reviewing process that is typically multi-disciplinary and with high acceptance rates (typically greater than $50 \%$ ).

Open-access-only Publishing mode that consists in only publishing online open access articles.

Predatory journals Journal with a near $100 \%$ acceptance rate and high APCs given the service provided.

Preprint Unreviewed manuscript posted online, often on dedicated servers such as arXiv, bioRxiv, or HAL. 
Table 1 Estimations of per article publishing costs for printed or online-only open access articles. Unless specified otherwise, the expense categories and the estimates originate from Hougton et al.'s report [6]. Their estimates were very conservative in 2009 and costs are likely to have dropped since. Here, we removed the $20 \%$ cost for Management and investment and the $20 \%$ cost for profits. Furthermore, the bioRxiv cost for online hosting was used [3]. The peer-reviewing cost is only shown for illustrative purposes and is not included in the calculations.

\begin{tabular}{|c|c|c|}
\hline Expense category & $\begin{array}{c}\text { Printed article } \\
\text { (non open access) }\end{array}$ & $\begin{array}{c}\text { Online only } \\
\text { ('gold' open access) }\end{array}$ \\
\hline Editing and proofreading & \multicolumn{2}{|c|}{ 610\$ (52\$ per page) } \\
\hline Author payment processing & & $25 \$$ \\
\hline Images and Graphics & $60 \$$ & less than $15 \$$ \\
\hline Composition and typesetting & $430 \$(35 \$$ per page $)$ & less than $108 \$$ ( $9 \$$ per page $)$ \\
\hline Quality content insurance & NA & $50 \$$ \\
\hline $\begin{array}{l}\text { Processing of non article types (e.g. perspectives, com- } \\
\text { mentaries) }\end{array}$ & $100 \$(1000 \$$ per issue $)$ & $10 \$(100 \$$ per issue $)$ \\
\hline Rights management & $65 \$$ & $13 \$$ \\
\hline Marketing & $150 \$$ & $50 \$$ \\
\hline Online hosting & NA & $10 \$[3]$ \\
\hline Customer service and helpdesk & $80 \$$ & $13 \$$ \\
\hline Sales administration and online user management & $125 \$$ & NA \\
\hline Printing and inventory management & $190 \$$ & NA \\
\hline Delivery and fulfilment & $125 \$$ & $40 \$$ \\
\hline Total & $1960 \$$ & $870 \$$ \\
\hline Total without proofreading & $1350 \$$ & $260 \$$ \\
\hline Peer-review process (for information) & \multicolumn{2}{|c|}{$800 \$$ per submitted article } \\
\hline
\end{tabular}

